\title{
Anatomical Description of Internal Vertebral Venous Plexus in Horses
}

\author{
Descripción del Plexo Venoso Vertebral Interno en Equinos
}

Romina Rojas Daveggio; Marcelo Gómez Jaramillo \& Pedro Aburto Valdebenito

ROJAS,D.R.; GÓMEZ, J.M.\& ABURTO, V.P. Anatomical description of internal vertebral venous plexus in horses. Int.J. Morphol., 36(2):527-530, 2018.

SUMMARY: The vertebral venous plexus is a vascular network that runs from the cervical to sacral vertebral canal in the spine of mammals. The objective of this study was to perform an anatomical study of the internal vertebral venous plexus (IVVP) in horses. The spine of five horse specimens (four adults and one foal) was dissected for morphological analysis of the IVVP. The IVVP was observed in the ventral epidural space of the vertebral canal and was composed by two symmetrical longitudinal veins. There was a difference in the IVVP diameter and morphology between foal and adult horses. In all the specimens, the IVVP was more developed at cervical segments, while a decrease in the IVVP diameter was seen in sacral and caudal segments. The cervical IVVP communicated cranially with the basilar, interbasilar and sigmoid sinuses. Transverse communicating branches between left and right IVVP were occasionally observed at the cervical, sacral and caudal vertebral segments. In conclusion, the IVVP in horses is similar to other domestic animals, has transverse connections and is more developed at cervical segment. The diameter of the longitudinal veins decreased and at the caudal segment reaches its thinnest development.

KEY WORDS: Veins; Internal vertebral venous plexus; Horses; Anatomy.

\section{INTRODUCTION}

The vertebral venous plexus (VVP) is also known as the epidural venous plexus, longitudinal spinal veins, vertebral sinuses (Caballero et al., 2012) or Batson's plexus (Junquera et al., 2004). The VVP is a venous network associated with the vertebral column that goes from the cervical to sacral segments (Tobinick, 2010). The VVP components are the basivertebral veins (BV), the external vertebral venous plexus (EVVP) and the internal vertebral venous plexus (IVVP) (Gómez Jaramillo \& Freeman, 2003; Arzone et al., 2008; Tobinick). The IVVP is located over the vertebral body's surface, on ventral epidural space contributing to venous drainage of the spine and surroundings, but it is also considered an alternative route for venous return (Gómez Jaramillo \& Freeman and Morales \& Montoliu, 2012). Since there is not much information about the horse's spine vasculature and its components, the objective of this work was to perform a morphological description of the IVVP in a sample of horses using anatomical dissection.

\section{MATERIAL AND METHOD}

The study was performed at the Veterinary Anatomy lab of the Institute of Pharmacology and Morphophysiology, Faculty of Veterinary Science at Austral University of Chile (UACh). For the study, five horse specimens (from 1 month to 20 years old) were used with no breed or sex distinction. All animals used in this study were donated and they were euthanized for different disease conditions excluding infectious, vascular, degenerative or traumatic pathologies associated to the spine or nervous system.

The equipment used included a digital camera (Canon SX500, 16 megapixels), a cold room $(3.1 \times 4 \mathrm{~m})$ for storing at $0^{\circ}-1{ }^{\circ} \mathrm{C}$ degrees, a $700 \mathrm{w}$ Skil emery and a Dremel Multimax MM40 to facilitate spine dissection. Measurements of the venous structures were taken with a manual caliper. For tissue conservation, an antifungal and conservative solution were used (composed by 8 parts of distilled water, 1 part of formaline $37 \%, 1$ part of $95 \%$ alcohol, thymol crystals, glycerine and eucalyptus essence). 
For specimen preparation, two techniques were used. The first one ( 2 horses) included euthanasia and fixation of the anatomical material. Initially, an intravenous injection of heparin was administered $(25,000 \mathrm{UI} /$ animal $)$ as anticoagulant. At cervical level, a skin incision and muscular blunt dissection was performed to expose the common carotid artery. Then, a catheter was inserted into the artery in order to administrate the fixation solution $(40 \mathrm{~L}$ of mixture $1450 \mathrm{~kg}$ ). Afterwards, the specimen was kept on a cold room at $0{ }^{\circ} \mathrm{C}$ for one week and then an anatomic dissection was performed. In the second method, a fresh dissection was performed in 3 horse specimens obtained from the Necropsy lab of the Animal Pathology Institute, UACh. These specimens were clinical cases of Veterinary Teaching Hospital at UACh and they either died or were euthanized in necropsy for post mortem study. Every vertebral column (From $\mathrm{C} 1$ to S3) was separated from the horses and then transferred to the Anatomy lab for morphological analysis. An epiaxial muscular dissection was performed in all animals (trapezius, spinal and semispinal, rhomboid, oblique, longissimus, multifid and iliocostal muscles were removed), and a vertebral laminectomy exposed the vertebral canal.
The spinal cord was carefully removed by manual retraction and without damaging the associated vascular structures. The vertebral columns were kept on a cold room for conservation. A digital photographic recording of the epidural space was obtained from all specimens.

\section{RESULTS}

The IVVP was observed in the epidural space, ventral to the spinal cord and composed by two parallel, longitudinal and symmetrical veins (left and right components). These two veins were located laterally in the vertebral canal at the ventral epidural level, forming a rhomboidal pattern convergent in the mid vertebral body and divergent at the level of the intervertebral spaces (Fig. 1). At the level of the atlas, venous sinuses were observed, which later formed the two longitudinal veins of the IVVP. An axial branch corresponding to the interbasilar sinus was also observed (Fig. 2). This venous network was composed of 6 small veins ( 3 per side), which drained into the longitudinal IVVP veins at the first cervical vertebra (C1).

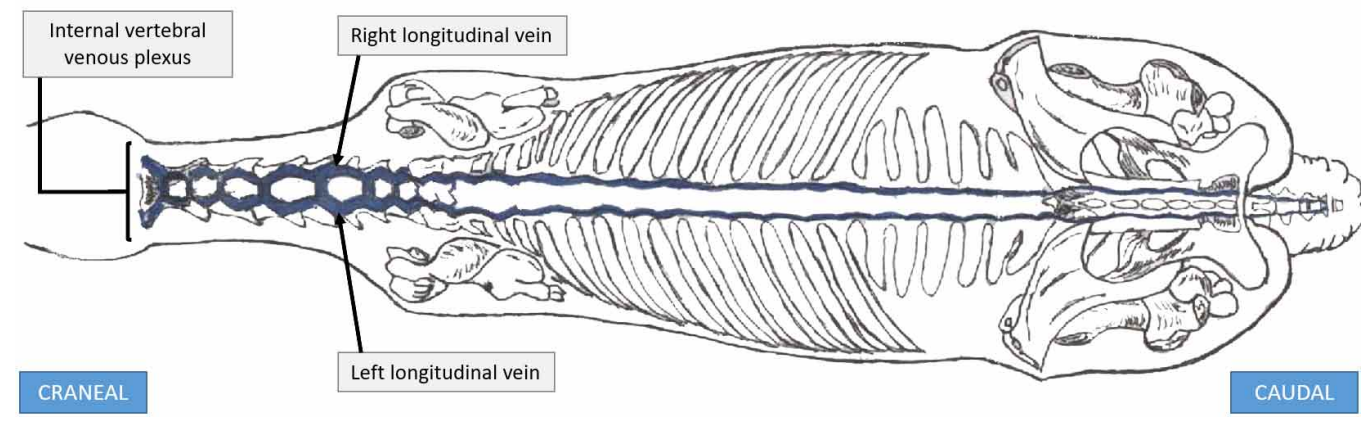

Fig. 1. Schematic representation of the IVVP in horses. The left and right longitudinal veins are seen along the vertebral canal. (Original image from Alex Rojas Zavala).

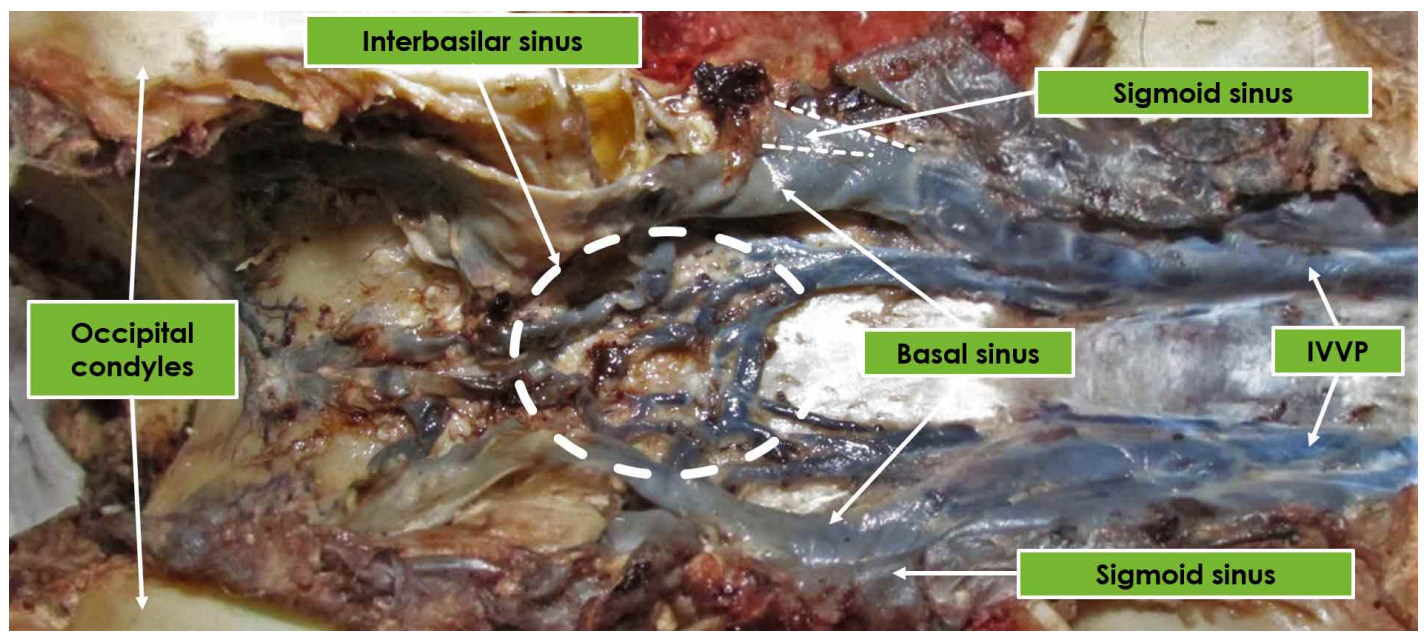

Fig 2. Dorsal image of atlanto-occipital transition of an adult horse. The cervical IVVP, basal sinus, sigmoid sinuses and interbasilar sinus are observed. 
The largest diameter of IVVP was observed in C1 and then was decreasing caudally. No transverse branches were seen between the cervical IVVP components in the foal, but other venous branches or anastomoses were observed at the level of the intervertebral space on the dorsal longitudinal ligament. In one adult horse transverse connections were observed between the cervical IVVP components. In one of the four adults, it was observed that the longitudinal components of the IVVP converged to connect in the intervertebral spaces. A decrease in IVVP diameter was observed in both longitudinal veins from the cervico-thoracic transition to caudally. This decrease in size was observed up to T9 and a then a slight increase of the thoracic IVVP diameter was evidenced. No transverse veins were found in thoracic IVVP segment of the foal, while there were some presents in adult IVVP between $\mathrm{T} 1$ and $\mathrm{T} 9$ segments (Fig. 3B).
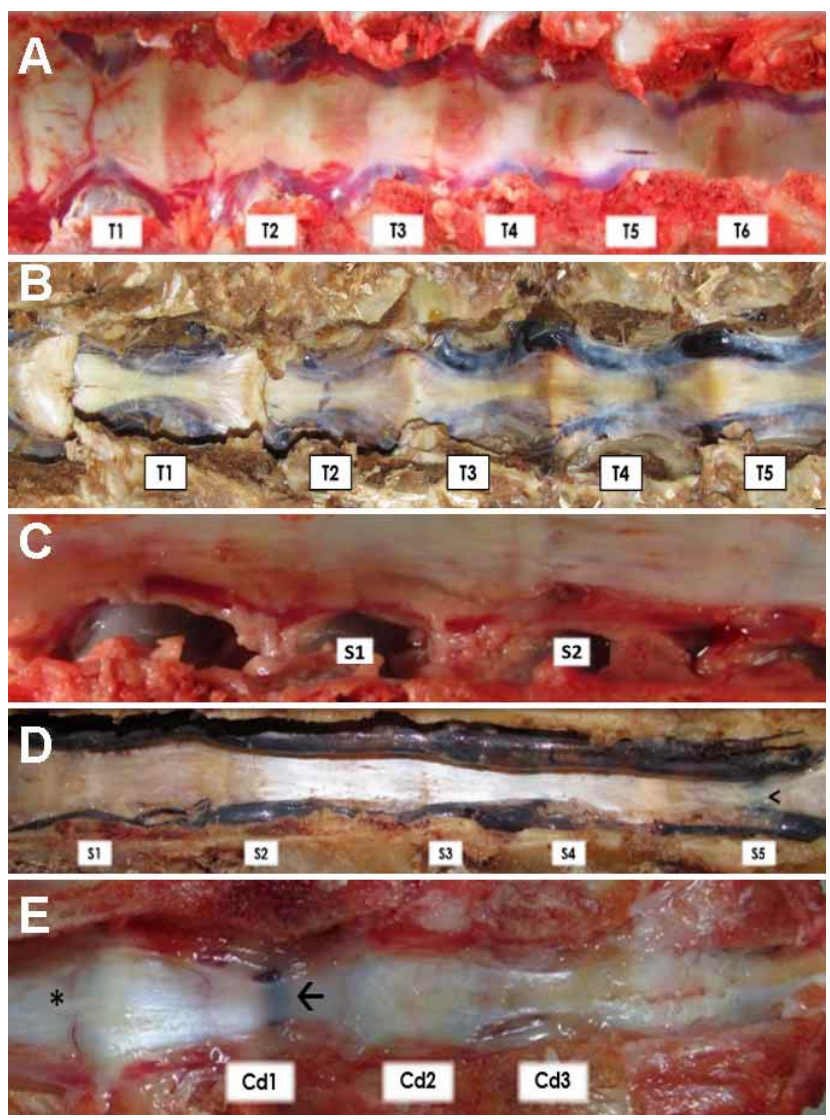

Fig 3. Dorsal images of IVVP in the horse, where cranial is at left and caudal at right of images. Longitudinal IVVP veins in thoracic segments of a 3-month (A) and 20-year-old (B) horse specimens. In the sacral segment (C) IVVP veins lack the rhomboidal arrangement. One adult (D) has venous branches $(<)$. The caudal IVVP segment in 2,5 year-old horse (E) has a progressive decrease in diameter. Transverse branch (arrow) and small superficial transverse veins $\left(^{*}\right)$ between IVVP are seen.
In the cranial lumbar section of all animals, the IVVP was observed with a smaller diameter than thoracic region. The lumbar IVVP of foals showed little development, reflected in a smaller diameter of veins and no venous branches in comparison with adults. In the sacral region, the IVVP show a smaller diameter and absence of the rhomboidal arrangement. At this segment, the foal showed little development being almost imperceptible to the level of the second sacral vertebrae. No transverse branches were observed in the sacral IVVP of foals (Fig. 3C). Only 1 horse presented a developed caudal IVVP (Fig. $3 \mathrm{E})$. The IVVP presented progressive diminution of diameter with small transverse branches in the sacro-caudal transition and a small transverse branch over the vertebral body of $\mathrm{Cd} 1$.

\section{DISCUSSION}

The IVVP in horses is formed by two parallel veins located in the vertebral canal, similar to reported for canines, bovines, camelids, cervids, primates and cetaceans (Gómez Jaramillo \& Freeman; Hoogland et al., 2012). These veins run the ventral vertebral canal from cervical to caudal segments. The IVVP arrangement has a rhomboidal pattern converging in the mid vertebral zone and diverging at intervertebral spaces as in other domestic species (Gómez Jaramillo \& Freeman; Arzone et al.; Hoogland et al.). In humans, the IVVP has an anterior and a posterior component (Demondion et al., 2000). This pattern is not described in other mammals, but the ventral IVVP of horses and other species is equivalent to the posterior IVVP described for humans (Gómez Jaramillo \& Freeman). As in dogs, camelids and humans, the horse IVVP is composed of longitudinal and transverse veins (Gómez Jaramillo \& Freeman; Arzone et al.; Tobinick). Transverse venous branches were observed connecting the longitudinal veins in cervical, sacral and caudal zones as observed in humans, primates and canines (Gómez Jaramillo \& Freeman; Hoogland et al.).

The animals included in this study were one foal, one young adult and three mature adults. The foal showed and IVVP diameter relatively smaller than adults, whereas the young adult specimen ( 2.5 years) showed IVVP diameters similar to the observed in the mature adult. The difference of IVVP morphometry between adult and young horses is consistent with the less development of the spinal venous network in human fetuses descriptions comparative with adult humans (Hoogland et al.). Animals have transverse communications of the IVVP in the cervical segment and with the interbasilar, sigmoid and basilar venous sinuses at cranio-cervical junction (Fig. 2), as seen in dogs (Schaller, 1992; Gómez Jaramillo \& Freeman). Venous sinuses of the nervous system are dilations located in the dura of the brain. 
Its function is the venous drainage of meninges and cerebrospinal fluid (Morales \& Montoliu). The abundant drainage of the meninges toward the IVVP increases the calibre of these veins contributing to the cushioning and protection of the spine (Gómez Jaramillo \& Freeman). Measurements of longitudinal IVVP veins showed that cervical segment has the biggest diameter, similar to that observed in dogs. Within the cervical segment, the highest IVVP diameter value were found in C1 (atlanto-occipital) and the lowest diameter at C7 (Gómez Jaramillo \& Freeman). In the cervico-thoracic transition, an abrupt decrease in the IVVP diameter of the horse specimens was observed. In other species, such as in dogs, humans, primates and cervids, the thoracic segment IVVP was smaller in relation to cervical segment (Gómez Jaramillo \& Freeman; Hoogland et al.).

Cranial (T1-T2) and caudal (T16-T18) thoracic segments presented a larger IVVP diameter. Neither in foal or adults, transverse venous branches were observed in the medial thoracic segment (between T9 and T18), as was reported by Gómez Jaramillo \& Freeman in adult dogs.

Lumbar IVVP in the foal was poorly developed, where the diameter of these veins was $50 \%$ minor than adults. Hoogland et al., observed a similar pattern in humans and canines, whereas in marine species it was different. Lumbar longitudinal IVVP veins of horses develop individually for each side of the vertebral canal, with no transverse venous branches as observed in cervids (Hoogland et al.). Contrary to that observed in horses, humans, non-humans primates and cetaceans have communications between right and left lumbar longitudinal veins. Venous networks are anastomosis of small branches communicating biggest veins (Hoogland et al.). In horses, primates, humans and cervids the left and right longitudinal veins were similar at lumbar region, but in cetaceans the IVVP showed a significant difference in longitudinal vein's size. Cetaceans and certain cervids are exposed to extreme ambient temperature and some authors think that special anatomic characteristics of IVVP as veins size, branches and valves are part of a thermoregulatory function of the IVVP, helping to protect the nervous system from extreme variations (Hoogland et al.).

CONCLUSIONS.The IVVP in horses has a similar morphology to that observed in other mammals. The cervical IVVP segment was more developed than other vertebral segments. Transverse vein connections between the IVVP were observed only on the cervical segment. The thoracic IVVP segment have less venous diameter than cervical IVVP segment. In the lumbar section, longitudinal IVVP veins appear to be parallel but decreasing in diameter and without transverse branches. Differences observed between foals and adult demonstrate that IVVP is less developed in youngest horses.
ROJAS, D. R.; GÓMEZ, J. M. \& ABURTO, V. P. Descripción del plexo venoso vertebral interno en equinos. Int. J. Morphol., 36(2):527-530, 2018.

RESUMEN: A lo largo de la columna vertebral de los mamíferos se extiende una red de vasos venosos conocida como plexo venoso vertebral interno (PVVI). Se realizó un estudio anatómico del PVVI en equinos mediante disección anatómica, donde se expuso el PVVI de 5 especímenes equinos (4 adultos y un potrillo) para estudio morfologico y registro fotográfico. El PVVI se observó en todo el espacio epidural espinal, conformado por dos venas longitudinales que recorrían el canal vertebral dispuestas de manera romboidal. Se observaron diferencias en el diámetro y morfología del PVVI de adultos en relación a lo observado en potrillos. El PVVI de equinos presentó su mayor desarrollo en el segmento vertebral cervical, disminuyendo el diámetro hacia caudal hasta desaparecer en la zona sacral o caudal. Se apreciaron ramas venosas transversales comunicando las venas longitudinales, destacando los senos venosos presentes en la zona cervical y las ramas transversas comunicantes en los segmentos cervical, sacral y caudal. En conclusión, el PVVI en equinos presentó un mayor desarrollo en la zona cervical y desde la zona torácica hacia caudal el PVVI disminuyó su desarrollo, siendo la zona caudal la más delgada.

PALABRAS CLAVE: Venas; Plexo venoso vertebral interno; Caballos; Anatomía.

\section{REFERENCES}

Arzone, C. A.; Sánchez, G. A.; Figueredo, R. V.; Acerbo, M. \& Pellegrino, F. C. Cervical venous circuit of the Llama (Lama glama). Int. J. Morphol., 26(4):849-52, 2008.

Caballero, G. J.; Felipe, M. A.; Toledo, V. C.; Pérez, O. P. \& Morales, P. I. Consideraciones anatomopatológicas y demográficas de la metástasis intracraneal. Rev. Cuba. Neurol. Neurocir., 2(1):23-7, 2012.

Demondion, X.; Delfaut, E. M.; Drizenko, A.; Boutry, N.; Francke, J. P. \& Cotten,A. Radio-anatomic demonstration of the vertebral lumbar venous plexuses: an MRI experimental study. Surg. Radiol. Anat., 22(3-4):1516,2000 .

Gómez Jaramillo, M. \& Freeman, L. Review of the vertebral venous plexus in the dog. Int. J. Morphol., 21(3):237-44, 2003.

Hoogland, P. V.; Vorster, W.; Groen, R. J. \& Kotzé, S. H. Possible thermoregulatory functions of the internal vertebral venous plexus in man and various other mammals: evidence from comparative anatomical studies. Clin. Anat., 25(4):452-60, 2012.

Junquera, L.; Rodríguez-Recio, C.; Torre, A.; Sánchez-Mayoral, J. \& Fresno, M. F. Metástasis mandibular por carcinoma hepático: un infrecuente caso con severa hemorragia. Med. Oral Patol. Oral Cir. Bucal, 9(4):3459, 2004.

Morales, C. \& Montoliu P. Neurología Canina y Felina. Madrid, Ultimédica Ediciones Veterinarias, 2012.

Schaller, O. Illustrated Veterinary Anatomical Nomenclature. Stuttgart, Ferdinand Enke, 1992. pp.362-3.

Tobinick, E. El sistema venoso cerebroespinal: Anatomía, fisiología e implicaciones clínicas. Arch. Med., 1(1):3, 2010.

Corresponding author:

Marcelo Gómez Jaramillo

Unidad de Anatomía Veterinaria

Facultad de Ciencias Veterinarias

Universidad Austral de Chile

Casilla 567 - Isla Teja

Valdivia - CHILE

Email: marcelogomez@uach.cl 